\title{
Arcabouço estratigráfico e ciclicidade deposicional dos sistemas sedimentares do Pleistoceno Médio-Holoceno da plataforma sul da Bacia de Campos, Brasil
}

\author{
Stratigraphic framework and depositional ciclicity of Middle \\ Pleistocene-Holocene sedimentary systems of the southern \\ shelf of Campos Basin, Brazil
}

\author{
Mariana Beltrão Marangoni ${ }^{1}$, Antonio Tadeu dos Reis ${ }^{1 *}$, Cleverson Guizan \\ Silva ${ }^{2}$, Renata Moreira da Costa Maia $^{2}$, Marina Rabineau ${ }^{3}$, \\ Josefa Varela Guerra ${ }^{1}$, Christian Gorini ${ }^{4}$, Rodrigo Arantes Oliveira ${ }^{1}$, \\ Mayara Morais Passos², Gabriela de Almeida Bernardo²
}

RESUMO: A análise sísmica de -3.000 km de dados sísmicos sparker de reflexão monocanal permitiu a proposição de um arcabouço estratigráfico englobando a seção rasa ( -300 milissegundos) da plataforma continental sul da Bacia de Campos. Cinco sequências sísmicas foram reconhecidas $(\mathrm{Sq} 1-\mathrm{Sq} 5)$, limitadas por superfícies erosivas de escala plataformal (superfícies S1 - S5), interpretadas como sequências deposicionais formadas por oscilaçóes glacioeustáticas e limites de sequências (discordâncias regionais) esculpidos durante longos períodos de exposiçẫo subaérea total da plataforma, indicando condiçóes de diminuição de nível de base e destruição parcial de espaço de acomodaçẫo sedimentar. As sequências Sq1 - Sq4 são dominantemente regressivas, compostas principalmente por prismas de regressão forçada de borda de plataforma/talude superior. A sequência superficial Sq5 é constituída essencialmente de unidades retrogradantes restritas à plataforma continental, interpretadas como compondo uma sequência eminentemente transgressiva. A correlaçáo entre dados sísmicos e cronoestratigráficos de um poço exploratório disponível na área permitiu posicionar a deposiçáo desta sucessão estratigráfica entre o Pleistoceno Médio-Holoceno (últimos - $500 \mathrm{ka}$ ). Além disso, a correlação entre a base de dados com curvas globais de variaçōes eustáticas, baseadas nas razóes isotópicas de $\delta^{18} \mathrm{O}$ (estágios isotópicos marinhos), permitiu ainda sugerir que a sucessão estratigráfica $\mathrm{Sq} 1$ - Sq4 registra sequências regressivas de quarta ordem, refletindo deposiçấo durante ciclos glacioeustáticos de $-100-120$ ka de duração e de alta amplitude de oscilaçáo eustática $( \pm 100-145 \mathrm{~m})$, que caracterizam o sinal eustático nos últimos - $500 \mathrm{ka}$. A sequência Sq5 seria uma sequência ainda em
ABSTRACT: Seismic analysis of about $3,000 \mathrm{~km}$ of sparker seismic lines allowed us to address a first order stratigraphic and stratal architecture scenario encompassing the shallow sedimentary record ( -300 milliseconds) of the southern continental shelf of Campos Basin, Brazil. Five major seismic sequences were identified (sequences Sq1 to Sq5), bounded by large margin-scale unconformities (horizons S1-S5). These seismic sequences were interpreted as a succession of depositional sequences induced by repeated glacio eustatic cycles limited by seismic horizons interpreted as master sequence boundaries, representing diachronous periods of erosion originated at times of deepest sea-level lowstands, related to periods of most extensive subaerial exposure of the shelf. These surfaces were reworked during subsequent times of sea level rise. Sequences Sq1-Sq4 are essentially composed of seaward-thickening stacks of forced-regression wedges, implying periods of declining accommodation space for sediments; whereas sequence Sq5 exhibit architectural elements of mostly transgressive units. Comparison between seismic lines and available chronostratigraphic data from the oil industry's exploratory wells made it possible to place the stratigraphic sequences Sq1-Sq5 within the Middle Pleistocene-Holocene interval (last - 500 kyr). Correlation of chronostratigraphic data and $\delta^{18} O$-derived information on glaciation-related global sea level variations (Marine Isotope Stages, MIS), also supports the hypothesis that sequences Sq1-Sq4 are fourth-order forced-regression sequences that record 100 - 120 kyr glacioeustatic cycles and high amplitude sea-level variations $( \pm 100-145 \mathrm{~m})$ for the last $-500 \mathrm{kyr}$, while deposits

${ }^{1}$ Faculdade de Oceanografia, Universidade do Estado do Rio de Janeiro - UERJ, Rio de Janeiro (RJ), Brasil. E-mail:mbeltraomarangoni@gmail.com, antonio.tadeu@pq.cnpq.br,josefa@uerj.br,pepe83@gmail.com

${ }^{2}$ Laboratório de Geologia Marinha - LAGEMAR, Departamento de Geologia, Universidade Federal Fluminense - UFF, Niterói (RJ), Brasil. E-mail: cguizan@id.uff.br, renata.ocn@gmail.com,mayara_mp@yahoo.com.br,gabizinhabernardo@hotmail.com

3Institut Universitaire des Sciences de la Mer - IUEM (UMR 6538), Université de Bretagne Occidentale - UBO, Brest, França. E-mail: marina.rabineau@univ-brest.fr ${ }^{4}$ Laboratoire Evolution et Modélisation des Bassins Sédimentaires, Institut de Science de la Terre - ISTEP (UMR CNRS 7193), Université Pierre et Marie Curie-Paris 6, Paris, França. E-mail: christian.gorini@upmc.fr

*Autor correspondente

Manuscrito ID 28075. Recebido em: 13/07/2012. Aprovado em: 04/04/2013 
formação, constituída por depósitos transgressivos e de mar alto formados durante o Pleistoceno Tardio-Holoceno.

PALAVRAS-CHAVE: plataforma continental; Pleistoceno-Holoceno; oscilaçóes glacioeustáticas. labeled as Sq5 are mostly represented by Latest Pleistocene-Holocene transgressive and highstand units.

KEYWORDS: continental shelf; Pleistocene-Holocene; glacioeustatic oscillations.

\section{INTRODUÇÃO}

Inúmeros estudos ao redor do globo revelam que as variaçôes climáticas e glacio-eustáticas pleistocênicas impactaram significativamente a evolução geológica das margens continentais, modificando sua construção e fisiografia, com marcantes implicaçôes sobre o desenvolvimento e evolução das plataformas continentais e dos ambientes costeiros, como estuários, deltas e planícies costeiras (por exemplo, Tesson, Posamentier \& Gensous 1993, Trincardi \& Correggiari 2000, Tesson, Posamentier \& Gensous 2000, Hernandez-Molina, Somoza \& Lobo 2000, Ridente \& Trincardi 2002, Jin, Chough \& Ryang 2002, Lofi et al. 2003, Rabineau et al. 2006, Grossman et al. 2006, Tezcan \& Okyar 2006, Liquete et al. 2008, Tripsanas \& Piper 2008).

Uma série de mudanças climáticas e oceanográficas, ocorridas entre $-1.250-700$ ka A.P., a chamada Transiçẫo do Pleistoceno Médio (The Middle Pleistocene Transition; Medina-Elizalde \& Lea 2005, Clark et al. 2006), levou ao surgimento de ciclos quase periódicos de baixa frequência de duração $(\sim 100-120 \mathrm{ka})$ e alta amplitude de oscilaçâo do nível do mar, cujo sinal eustático é reconhecido globalmente a partir de $\sim 800-700$ ka A.P. (Imbrie et al. 1984, Medina-Elizalde \& Lea 2005, Clark et al. 2006). Neste contexto, os últimos - 500 ka são caracterizados por grandes variaçōes eustáticas entre posiçóes próximas, ou levemente acima, da atual até -120/-145 m (por exemplo, Imbrie et al. 1984, Labeyrie, Duplessy \& Blanc 1987, Fairbanks 1989, Bard, Hamelin \& Fairbanks 1990, Bassinot et al. 1994, Shackleton 2000, Lambeck \& Chappell 2001, Waelbroeck et al. 2002). Estes estudos também evidenciam que ao longo dos últimos $900-$ $800 \mathrm{ka}$, as tendências transgressivas e os segmentos de mar alto das curvas glacio-eustáticas, associadas a intervalos climáticos quentes, representam menos de $10 \%$ do total dos ciclos de oscilaçôes eustáticas de $100-120 \mathrm{ka}$ de duração; ao passo que o restante do ciclo é dominado por fases mais longas de regressão marinha que culminam com intervalos igualmente curtos de máximos glaciais (Berné et al. 2004). Como a regiáo de quebra das plataformas continentais situa-se globalmente entre profundidades de 100 a 200 m, grandes porçôes das plataformas têm sido, assim, periodicamente expostas durante os longos períodos de resfriamento climático que marcam os últimos $\sim 500 \mathrm{ka}$ (Berné et al. 2004, Rabineau et al. 2006).

No entanto, são relativamente raros os estudos sobre a evolução estratigráfica das plataformas continentais brasileiras envolvendo o intervalo temporal dos últimos 500 ka. Maia et al. (2010) identificaram sequências deposicionais dominantemente regressivas na plataforma continental sul fluminense (Bacia de Santos), relacionadas às variaçôes glacio-eustáticas do Pleistoceno Médio-Holoceno, associadas à exposição cíclica da plataforma fluminense durante períodos regressivos de $-100-120$ ka de duração. $\mathrm{Na}$ área de estudo, Alves et al. (1980) foram os primeiros autores a relatar a presença de prismas progradacionais na borda da plataforma, mas tais feiçôes não foram discutidas em um contexto glacio-eustático. Posteriormente, alguns estudos abordaram a evolução sedimentar pleistocênica de porçóes da plataforma continental da área: Lopes (2004) identificou sequências sísmicas numa porção da plataforma interna-média à frente do Cabo de São Tomé, atribuídas às oscilaçôes climáticas do Pleistoceno Médio-Superior; enquanto Silva (1992) relatou a ocorrência de sucessão estratigráfica numa porção da plataforma média-externa da bacia, cuja deposiçấo foi atribuída aos últimos 440 - 500 ka. Contudo, estes trabalhos não focalizaram a arquitetura estratal das sequências, sua relação com os segmentos das curvas eustáticas, nem a variabilidade lateral das unidades sísmicas reconhecidas.

Deste modo, o presente estudo teve como objetivo investigar a organização do registro estratigráfico da plataforma sul da Bacia de Campos, focalizando as modificaçôes da arquitetura sísmica na sucessão estratigráfica imageada nos primeiros -300 milissegundos de penetração do registro sísmico de alta resolução (100 milissegundos equivalem a $80 \mathrm{~m}$ de espessura sedimentar, para uma velocidade sísmica intervalar de $1.600 \mathrm{~m} / \mathrm{s}$ ).

Este trabalho é parte integrante de um projeto mais amplo de investigação dos ambientes deposicionais da plataforma continental ao largo do Estado do Rio de Janeiro, entre a Baía de Ilha Grande e a Foz do Rio Itabapoana, e sua acoplagem estratigráfica aos atuais ambientes costeiros, desenvolvido no âmbito de um programa CAPESCiências do Mar entre a Faculdade de Oceanografia da Universidade do Estado do Rio de Janeiro (UERJ) e o 
Departamento de Geologia-LAGEMAR da Universidade Federal Fluminense (UFF), intitulado "Estudos oceanográficos e geológico-geofísicos integrados nos ambientes de baías e de plataforma continental ao largo do Estado do Rio de Janeiro".

\section{ÁREA DE ESTUDO}

A área de estudos envolve a plataforma continental norte fluminense, localizada entre Cabo Frio ( $\left.23^{\circ} 16^{\prime} S\right)$, a sul, e Cabo de São Tomé ( - 21058'S), a norte, correspondendo à porçấo sul da plataforma continental da Bacia de Campos (Fig. 1). Esta plataforma possui largura variável entre $-64 \mathrm{~km}$, imediatamente a sul do Cabo de São Tomé, com profundidade de quebra em -130 m, a
$98 \mathrm{~km}$ à frente do Cabo Frio, onde apresenta profundidade de quebra em - -150 m (Figs. 1 e 2). A plataforma apresenta também variaçóes morfológicas marcantes no sentido continente-bacia, sendo a plataforma interna/ média (até $-70-80 \mathrm{~m}$ de profundidade) caracterizada por morfologia convexa, enquanto em direção à quebra de plataforma o fundo submarino apresenta uma morfologia côncava (Marangoni 2012). Gradientes elevados de - 0,243-0,578 ${ }^{\circ}$ marcam a transição entre os domínios de plataforma interna/média e externa, configurando feiçóes lineares ao longo das isóbatas de 70 e 80 m (Figs. 1 e 2). A linha de costa, assim com a linha de quebra da plataforma da bacia, apresenta direção geral NE-SW.

Em termos regionais, a Bacia de Campos, limitada pelo Alto de Cabo Frio, ao sul, e Alto de Vitória, ao norte, marca uma notável inflexão da direção geral E-W que caracteriza

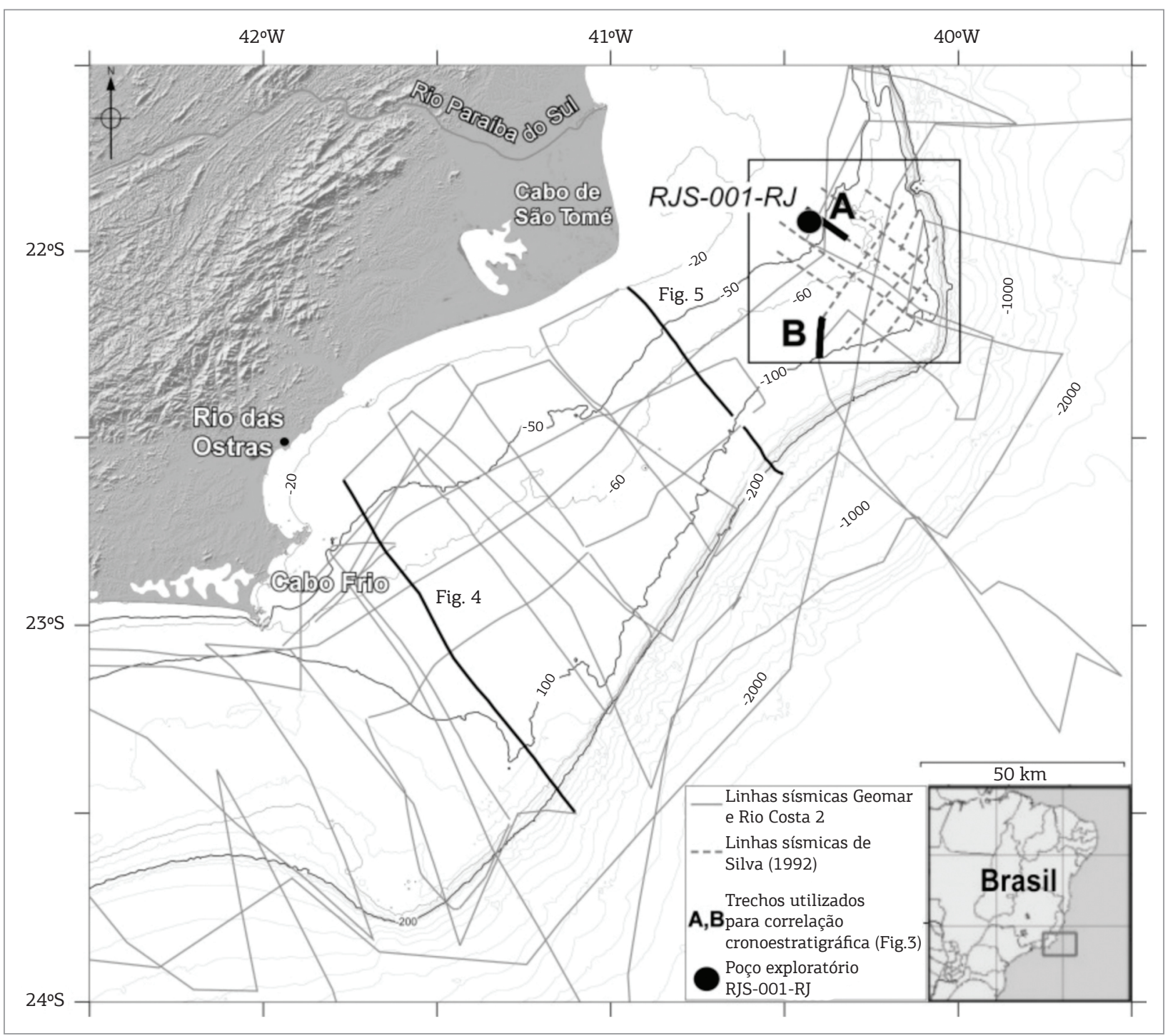

Figura 1. Mapa de localização da área de estudo, e da base de dados sísmicos e cronoestratigráficos utilizados neste trabalho. 
a margem continental sul fluminense (Bacia de Santos), para uma direção geral NE-SW que caracteriza as direçóes de linha de costa e de quebra da plataforma continental na área (Fig. 1). Segundo Chang et al. (1992), esta inflexão, na região de Cabo Frio, foi induzida por antigos lineamentos crustais da margem leste brasileira, responsáveis por mudanças na orientação das estruturas do estiramento litosférico entre as Bacias de Santos e de Campos durante o Cretáceo Inferior, quando da propagaçáo Sul-Norte da ruptura do megacontinente Gondwana, originado mais ao sul do continente. A atual morfologia da margem, caracterizada por plataforma-talude, é resultante, por sua vez, da evolução tectono-sedimentar da bacia e pela presença do Rio Paraíba do Sul (Cainnelli \& Mohriak 1999, Modica \& Brush 2004).

O espesso empilhamento sedimentar $(\sim 7.000 \mathrm{~m}$ na altura do talude continental) é composto por cinco megassequências sedimentares (Chang et al. 1992). Elas refletem a evolução tectono-sedimentar da bacia a partir de ambiente sedimentar continental (a chamada Megassequência Sin-rifte), passando pela deposição de uma Megassequência Evaporítica, que marca a transição entre a deposição sin-rifte para uma deposição marinha restrita (Megassequência Carbonática), até a implantação de ambientes francamente marinhos num contexto de subsidência térmica da margem — as chamadas Megassequências Marinhas Transgressiva e Regressiva. A Megassequência Marinha Transgressiva formou-se sob um forte aprofundamento da bacia, resultante de mais elevadas taxas de subsidência térmica, até a transição Cretáceo Superior-base do Terciário. A amplificação de sua área e a deposição de intervalos estratigráficos em estilo retrogradante resultaram numa morfologia de margem em rampa

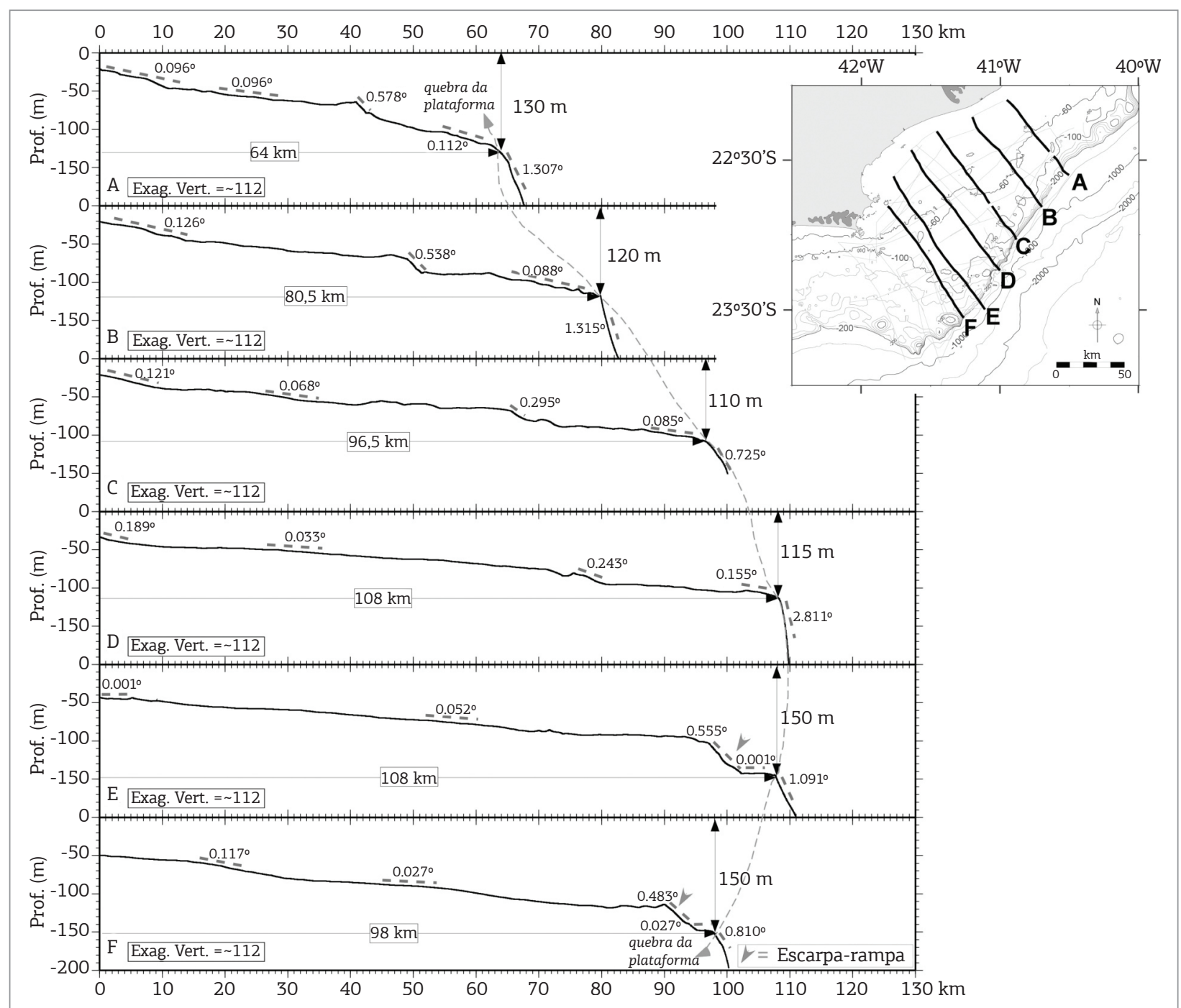

Figura 2. Série de perfis morfológicos extraídos dos dados batimétricos gridados General Bathymetric Chart of the Oceans, GEBCO_08 Grid - versão 20090202, ilustrando as dimensões, gradientes, profundidades de quebra e variações morfológicas da plataforma continental norte do Estado do Rio de Janeiro, porção sul da Bacia de Campos. 
(Cainnelli \& Mohriak 1999). Esta fase foi seguida da deposição de estratos sedimentares fortemente progradacionais (a Megassequência Marinha Regressiva), desenvolvidos em função da diminuição da taxa de subsidência térmica e aumento da taxa de aporte sedimentar, levando ao desenvolvimento de cunhas sedimentares em offlap (clinoformas progradantes; Mitchum Jr., Vail \& Sangree 1977a, 1977b), que modelaram a morfologia hoje constituída por plataforma e talude continental como conhecemos (Chang et al. 1992). Um fluxo significativamente maior de terrígenos chegou à bacia a partir do Oligoceno Inferior, quando o sistema de drenagem correlacionável a um Rio Paraíba do Sul ancestral (Modica \& Brush 2004) foi estruturalmente desviado da Bacia de Santos para a de Campos, culminando com o grande espessamento da megassequência durante o Terciário Superior (espessuras > $3.500 \mathrm{~m}$; Chang et al. 1992).

A sucessão estratigráfica, focalizada no presente trabalho, constitui o topo da Megassequência Marinha Regressiva na plataforma continental da bacia $(-200-$ $250 \mathrm{~m}$ de espessura sedimentar superficial), pois permanece desconhecido como esta sucessão estratigráfica respondeu às oscilaçóes glacio-eustáticas de alta amplitude que caracterizam os últimos $\sim 500$ ka (Pleistoceno MédioHoloceno), seus principais elementos arquiteturais, o grau de preservação de diferentes sequências deposicionais, assim como sua variabilidade lateral.

\section{MATERIAL E MÉTODOS}

Este estudo dispóe de $-3.000 \mathrm{~km}$ de perfis de sísmica de reflexáo monocanal, compreendendo 2 conjuntos de dados: (1) - $2.000 \mathrm{~km}$ de perfis recentemente coletados com sistema Sparker modelo SQUID 2000, Applied Acoustics Engeneering Ltda (potência de $700 \mathrm{~J}$ e penetração do sinal acústico de cerca de 250 - 300 milissegundos), durante a Missão Oceanográfica Rio Costa II (agosto de 2011), realizada a bordo do navio de pesquisa AvPq Aspirante Moura, do Instituto de Estudos do Mar Almirante Paulo Moreira da Marinha do Brasil (IEAPM) (Fig. 1). Estes dados foram processados no próprio sistema de aquisição sísmica, modelo CODA 500, através da aplicação de filtros para melhoria da razão sinal/ruído e de filtros do tipo swell filter, para retirada dos ruídos de ondas do mar. (2) - 1.000 km de dados sísmicos analógicos, já existentes, adquiridos com fonte Sparker (potência de 500 - 1.000 J e penetração de cerca de 300 milissegundos), coletados nos anos 1980 durante as Operações GEOMAR XII, XVI e XX ${ }^{1}$ (Fig. 1).

As correlaçóes cronoestratigráficas foram feitas a partir de dados do poço exploratório RJS-001-RJ cedido pela Agência Nacional do Petróleo (ANP), cujo topo foi redatado (bioestratigrafia por zonação de nanofósseis) por Shimabukuro $^{2}$ (1989 apud Silva 1990), que foram calibradas em linhas sísmicas industriais 2D interpretadas por Silva (1992), disponibilizadas para cruzamento com os dados sísmicos do presente trabalho (Figs. 1 e 3). Na ausência de curvas de variaçóes eustáticas pleisto-holocênicas para a plataforma estudada, foram utilizadas curvas globais de variaçóes eustáticas baseadas na razão isotópica de $\delta^{18} \mathrm{O}$, compiladas por Rabineau et al. (2006).

A interpretação dos perfis sísmicos foi feita segundo os princípios gerais da sismoestratigrafia e da estratigrafia de sequências de alta resolução sintetizados, respectivamente, em Mitchum Jr., Vail \& Sangree (1977a, 1977b) e Catuneanu (2006). Esta etapa permitiu a identificaçáo das principais unidades deposicionais, de suas superfícies limitantes, assim como de fácies sísmicas indicativas da presença de diferentes ambientes sedimentares. Para cálculo de espessura sedimentar, tanto de unidades siliciclásticas como carbonáticas, foi estimada uma velocidade intervalar única de $1.600 \mathrm{~m} / \mathrm{s}$ (por exemplo, cada 100 milissegundos de trajetória de ida-volta do sinal acústico equivalem a $80 \mathrm{~m}$ de espessura).

\section{RESULTADOS}

A análise sismoestratigráfica empreendida mostra que a seção estratigráfica compreendida nos $\sim 250 \mathrm{~m}$ de espessura sedimentar da plataforma sul da Bacia de Campos é composta por 5 sequências sísmicas principais, denominadas Sq1, Sq2, Sq3, Sq4 e Sq5, limitadas por superfícies lateralmente correlacionáveis na escala de toda a plataforma continental da área - as superfícies S1, S2, S3, S4, S5 e S6. Em alguns perfis sísmicos, a superfície $S 1$ representa o limite basal de penetração do sinal acústico, abaixo do qual o pobre imageamento dificulta o reconhecimento e correlaçáo lateral de unidades sísmicas na plataforma (Figs. 4 e 5).

As sequências sísmicas Sq1-Sq4 se caracterizam por apresentar clinoformas progradantes que se espessam na direção

${ }^{1}$ Os cruzeiros oceanográficos GEOMAR (num total de 24 cruzeiros científicos) são um produto de esforços conjuntos da comunidade científica nacional, através do Programa de Geologia e Geofísica Marinha (PGGM), e da então Diretoria de Hidrografia e Navegação, Marinha do Brasil, hoje Centro Hidrográfico da Marinha (CHM), realizados entre 1969 e 1986 para a coleta de dados de sísmica rasa monocanal, perfilagem de subfundo e amostragens superficiais na margem continental brasileira.

${ }^{2}$ Shimabukuro, S. (1989). Comunicação pessoal baseada em análise e reinterpretação do conteúdo micropaleontológico do poço RJS-001-RJ feitas na Petrobras em 1989 (localização do poço na Fig. 1). 
do gradiente deposicional (em direção à plataforma exter$\mathrm{na})$, apresentando espessuras entre $-5-22 \mathrm{~m}$ na plataforma interna-média (70 - $80 \mathrm{~m}$ de profundidade atual), e - 20 $48 \mathrm{~m}$ na altura das respectivas paleoquebras de plataforma (Figs. 4 e 5). No entanto, estas sequências apresentam diferenças arquiteturais no seu empilhamento vertical e na sua distribuição lateral entre a porção sul e norte da plataforma.

As sequências sísmicas mais basais Sq1 e Sq2 são compostas por clinoformas progradantes que se desenvolvem apenas a partir da plataforma interna-média, cujas posiçóes de alcance interno se ampliam da Sq1 para Sq2. Os refletores internos das clinoformas são inclinados e terminam em truncamento erosivo contra superfícies-topo de extensão limitada, que se amalgamam em direção ao continente com a superfície $S 1$, para se tornarem superfícies de extensão plataformal (superfícies S2 e S3; Figs. 4 e 5). As clinoformas que compóem estas sequências são geometricamente distantes, e apresentam diferentes configuraçóes de reflexôes internas, entre a porção sul e norte da plataforma: (a) no sul da área, à frente de Rio das Ostras, as clinoformas são oblíquas-paralelas (no sentido de Mitchum Jr., Vail \& Sangree 1977a), de menores espessuras relativas (entre - $20-28 \mathrm{~m}$ ), com refletores internos terminando em downlap e toplap contra superfícies limitantes

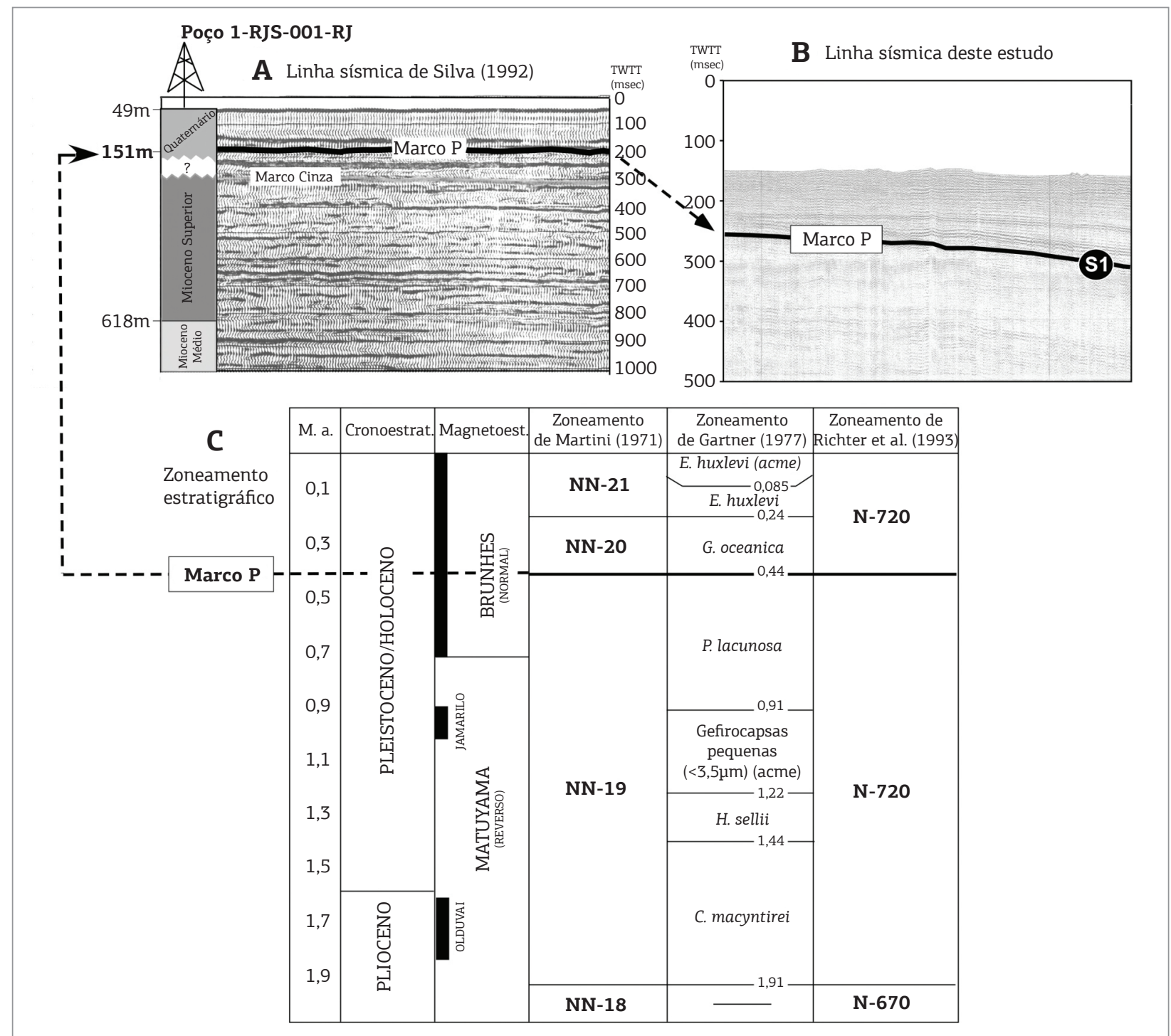

Figura 3. (A) Coluna sintética dos dados cronoestratigráficos do poço exploratório RJS-001-RJ, cedido pela Agência Nacional do Petróleo, calibrado sobre linha sísmica de Silva (1992) disponibilizada para este trabalho. (B) Linha sísmica do presente estudo utilizada para cruzamento e correlação estratigráfica com os dados interpretados por Silva (1992). (C) Quadro de biozonação de nanofósseis de Antunes (1994), para posicionamento estratigráfico das amostras analisadas por Shimabukuro² (1989, apud Silva, 1992) que apontam a presença de Pseudoemiliania lacunosa (correlacionada ao topo da biozona N710), em sedimentos logo abaixo do chamado Marco P. 


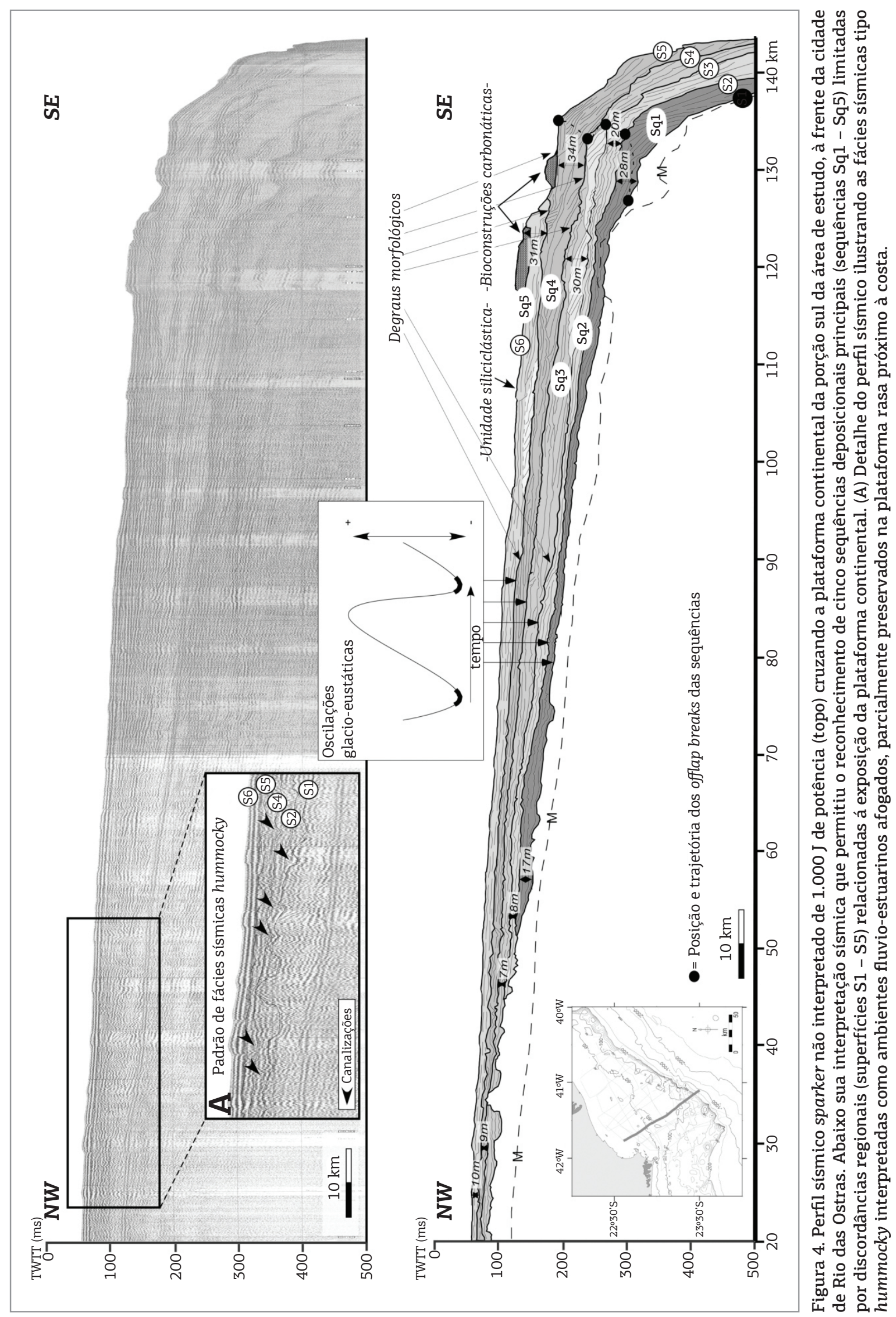




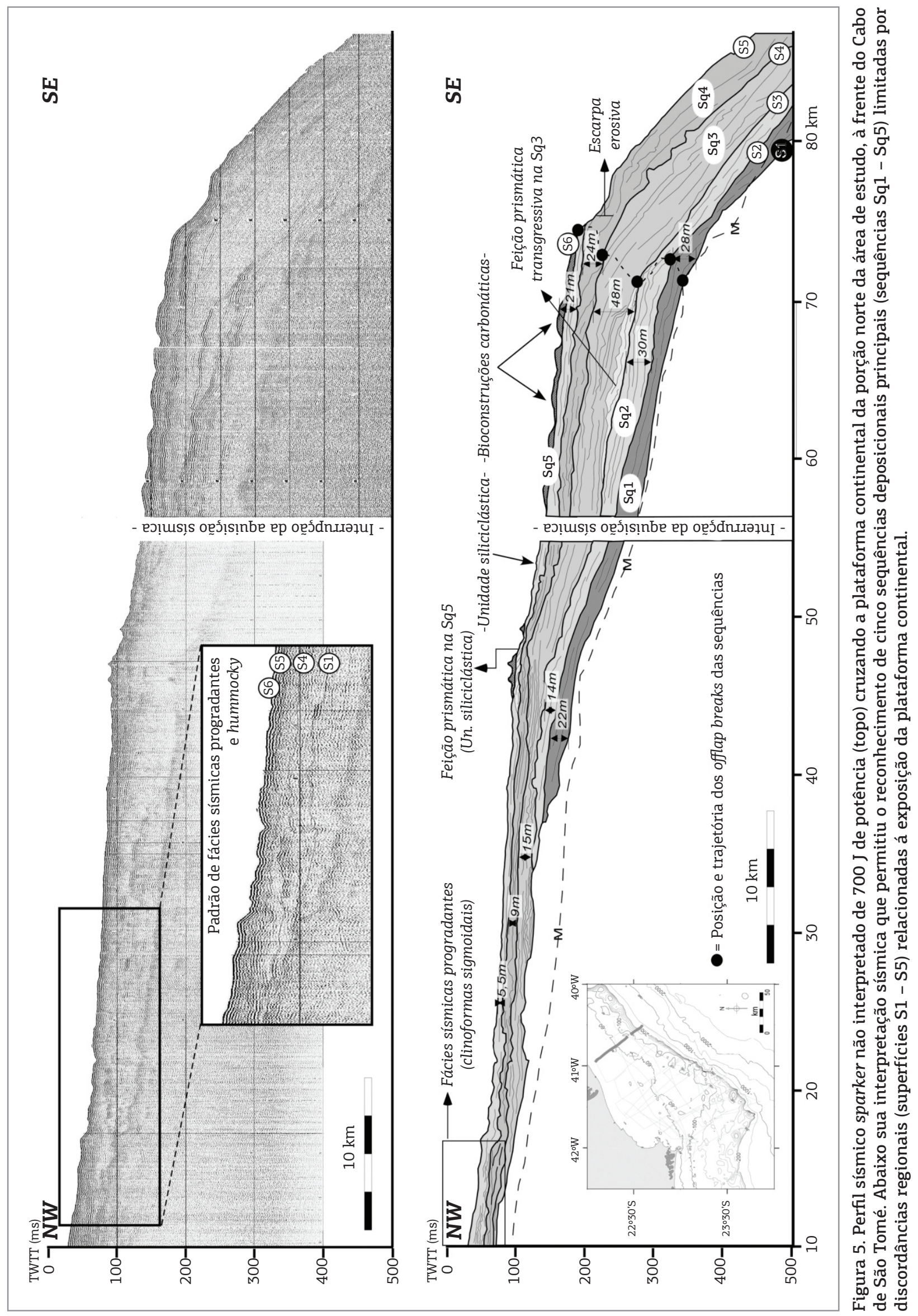


levemente inclinadas em direção ao mar (superfícies S1, S2 e S3; Fig 4). Estas clinoformas são interpretadas como ambientes de alta energia, refletindo a migração constante de ambientes sedimentares siliciclásticos costeiros/marinhos rasos em direção ao mar, tendo as superfícies-topo S2 e S3 representado o nível de base local para erosão, ou tendo estado próximas a ele. Os pontos de inflexão entre refletores inclinados (foresets, no sentido de Mitchum Jr., Vail \& Sangree 1977a) e a superfície-topo das clinoformas (superfícies S2 e S3), podem ser interpretados como a transição entre ambientes costeiros, progressivamente erodidos, e ambientes marinhos rasos (estratos inclinados) (Mitchum Jr., Vail \& Sangree 1977a, Henriksen, HellandHansen \& Bullimore 2011) (Fig 4). (b) Já ao norte, próximo à região à frente do Cabo de São Tomé, as clinoformas oblíquas apresentam geometria com tendência tangencial (componentes deposicionais em agradaçáo), exibindo refletores internos de mais baixo ângulo terminando contra superfícies limitantes mais irregulares, que formam feiçóes depressionadas na regiáo de plataforma externa; tais clinoformas resultam em unidades deposicionais relativamente mais espessas (entre $-28-30 \mathrm{~m}$ ) que na porção sul da plataforma (Fig. 5). Estas clinoformas são também interpretadas como ambientes de alta energia relativa, representando a migração constante de ambientes siliciclásticos costeiros/marinhos rasos em direção ao mar. Contudo, o caráter agradacional dos estratos inclinados (foresets), assentando-se sobre superfícies deposicionais basais de mais forte inclinação (superfícies S1 e S2), sugere criação de maior espaço de acomodaçáo nesta porçáo da margem e a deposição de estratos inclinados em ambientes marinhos progressivamente mais profundos, levemente abaixo do nível de base local para erosão (Mitchum Jr., Vail \& Sangree 1977a, Henriksen, Helland-Hansen \& Bullimore 2011).

As sequências sísmicas Sq3 e Sq4 exibem maior variabilidade de fácies sísmicas internas e geometrias externas, assim como diferentes extensôes em direção ao continente (posição do alcance interno) (Fig. 4 e 5). Na regiáo de plataforma interna-média, estas sequências são compostas por unidades tabulares, caracterizadas por refletores subparalelos e/ou ondulados, descontínuos, entremeados com refletores caóticos e pequenas canalizaçóes superpostas em complexo arranjo de corte e preenchimento, compondo uma fácies sísmica do tipo hummocky (no sentido de Mitchum Jr., Vail \& Sangree 1977a), com espessuras entre -515 m (Figs. 4A e 5). Fácies hummocky recobrindo a porção de plataforma interna-média são aqui interpretadas como ambientes fluvio-estuarinos preservados à frente da atual planície costeira do Rio Paraíba do Sul. Esta fácies transiciona em direção à plataforma externa para clinoformas progradantes (Figs. 4 e 5). O conjunto de fácies hummocky-clinoformas progradantes compóe sequências de extensão plataformal, observadas até a região costeira rasa (limite interno da perfilagem sísmica disponível), e avançando distalmente sobre o talude superior. Da mesma forma que nas sequências mais basais, estas sequências apresentam diferenças arquiteturais entre a porção sul e norte da plataforma estudada: (a) à frente de Rio das Ostras, uma sucessão de clinoformas oblíquas-paralelas migra em direção à quebra de plataforma com seus refletores internos terminando em downlap contra as superfícies basais (superfícies S3 e S4; Fig. 4); as superfícies-topo das sequências formam degraus morfológicos que se aprofundam em direçấo à quebra de plataforma, truncando as reflexôes internas das sequências em relação de toplap (superfícies S4 e S5; Fig. 4); estas clinoformas apresentam espessuras máximas entre $-30-34 \mathrm{~m}$ na altura das respectivas paleoquebras de plataforma (Fig. 4). Tal como nas sequências Sq1 e Sq2, clinoformas oblíquas-paralelas indicam a migração de ambientes sedimentares siliciclásticos costeiros/marinhos rasos em direção ao mar, ao longo de superfícies-topo (superfícies S4 e S5) que representaram o nível de base local para erosão, ou estiveram próximos a ele. Estas clinoformas são interpretadas como a transição entre ambientes costeiros, progressivamente erodidos, e ambientes marinhos rasos (estratos inclinados) (Henriksen, Helland-Hansen \& Bullimore 2011) (Fig. 4). (b) Ao norte, próximo à região à frente do Cabo de São Tomé, as clinoformas da plataforma externa tendem a sigmoidais, resultando em unidades agradacionais, que atingem espessuras individuais da ordem de $-24-48 \mathrm{~m}$, relativamente mais espessas que na porção sul da plataforma (Fig. 5). Somente na porção mais distal da plataforma/talude superior, as clinoformas adquirem caráter mais oblíquo, com claro truncamento erosivo pelas superfícies-topo S4 e S5 (Fig. 5). Estas clinoformas progradantes são também interpretadas como ambientes de alta energia relativa, refletindo a migração de ambientes sedimentares siliciclásticos costeiros/ marinhos rasos em direção ao mar. Contudo, nesta porção da plataforma elas apresentam geometrias mais sigmoidais e maior caráter agradacional, o que aponta para a disponibilização de maior espaço de acomodação (Henriksen, HellandHansen \& Bullimore 2011) durante sua deposição (principalmente a sequência Sq3; Fig. 5).

A sequência superficial Sq5 é limitada na base pela superfície $S 5$ e no topo pela superfície S6 - o fundo submarino na quase totalidade da plataforma continental. Ela se distingue das demais sequências por apresentar forma externa geral tabular, dominada por refletores internos plano-paralelos contínuos, distribuída a partir da plataforma interna/média até a plataforma externa, sem recobrir a borda de plataforma nem apresentar clinoformas progradantes distais. Próximo à costa, as reflexôes plano-paralelas dão lugar a fácies sísmicas do tipo hummocky, indicativas de paleoambientes fluvio-estuarinos afogados, como 
recentemente identificados em trabalhos na área, baseados em imageamento sísmico com fonte do tipo boomer de maior resolução (Bernardo 2012, Passos 2012) (Fig. 4A). Estas unidades tabulares são mais espessas na porção sul ( $10-20$ m de espessura; Fig. 4) que na porção norte da plataforma ( $-510 \mathrm{~m}$ de espessura; Fig. 5). Este conjunto de fácies sísmicas reflectivas foi interpretado como representando depósitos siliciclásticos (Figs. 4 e 5). Ao longo de toda a plataforma externa (abaixo de $-70-80 \mathrm{~m}$ de profundidade), o topo da sequência é marcado pela ocorrência de corpos isolados, com ausência de reflexão interna, que se desenvolvem sobre as unidades sedimentares siliciclásticas distais. Estes corpos formam bancos ou pináculos de até $-8-15 \mathrm{~m}$ de espessura e $-2,5-7,0 \mathrm{~km}$ de largura (Fig. 4), ou corpos de igual espessura mas de forma externa irregular, apresentando até $17 \mathrm{~km}$ de extensão no sentido do gradiente (Fig. 5). Estas fácies encontram-se assentadas sobre as unidades sedimentares siciliciclásticas basais e foram interpretadas como bioconstruçôes carbonáticas baseadas em suas fácies sísmicas (Mitchum Jr., Vail \& Sangree 1977a). Elas contribuem para o espessamento local da sequência Sq5, que pode atingir -30 m (Fig. 4). Este microrrelevo carbonático reconhecido sismicamente neste estudo, já foi anteriormente repertoriado e amostrado na plataforma fluminense (Kowsmann, Vicalvi \& Costa 1979, Figueiredo Jr. \& Tessler 2004).
As três sequências sísmicas superiores $\mathrm{Sq} 3$ - Sq5 contêm alguns elementos arquiteturais distintos, representados por feiçôes prismáticas progradantes preservadas na base das sequências na regiáo de plataforma média-externa e borda de plataforma, principalmente na porção sul da plataforma continental (Fig. 4). Trata-se de prismas compostos por clinoformas progradantes, oblíquas-paralelas, de pequenas dimensóes: $-7,5-15 \mathrm{~km}$ de extensão no sentindo do gradiente e espessuras de $-9-20 \mathrm{~km}$ (Fig. 6). O assentamento destes prismas diretamente sobre superfícies de discordância regional permite sua interpretação como feiçóes depositadas durante eventos transgressivos. A ocorrência de feiçóes prismáticas semelhantes já foi relatada por Rabineau et al. (2006) na plataforma do Golfo de Lion, atribuídas a prismas arenosos praiais depositados por retrabalhamento durante rápida transgressão, característicos de plataformas deltaicas sob influência de alto aporte sedimentar fluvial, como é o caso da plataforma do Golfo de Lion sob influência do delta do Rio Róldano (Rhône).

\section{DISCUSSÃO}

A análise sísmica da base de dados disponível permitiu a individualização de uma série de sequências sísmicas (Sq1 - Sq5) definidas por conjuntos de sismofácies

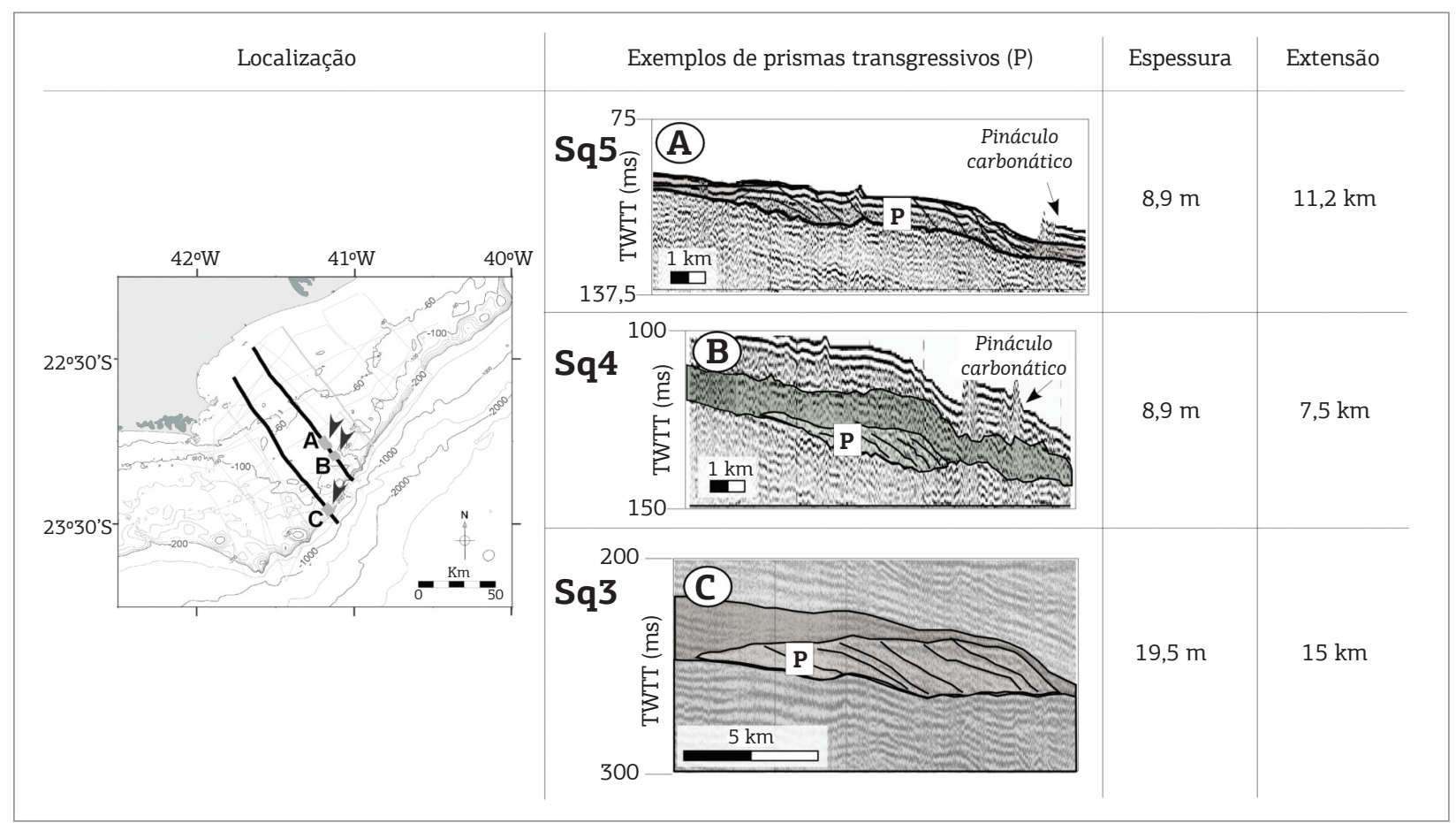

Figura 6. A, B e C são trechos de perfis sísmicos sparker (700 - 1.000 J), ressaltando o reconhecimento de feições prismáticas observadas na base das sequências Sq3, Sq4 e Sq5, atribuídas a prismas arenosos praiais depositados por retrabalhamento durante rápida transgressão, característicos de plataformas deltaicas sob influência de alto aporte sedimentar fluvial. 
características. Estas sequências são limitadas por superfícies marcadas por acentuada irregularidade (superfícies S1 - S5), sugerindo a ocorrência cíclica de processos erosivos amplamente distribuídos na escala regional da plataforma continental. A amplitude espacial de tal erosáo aponta para ocorrência de períodos de longa duração de exposição subaérea da plataforma como responsáveis pela formação das discordâncias (Figs. 4 e 5), interpretadas como superfícies limites de sequências deposicionais (Sequence boundary, no sentido de Hunt \& Tucker 1992, Plint \& Nummedal 2000).

\section{Arquitetura deposicional dos sistemas plataformais}

A análise sísmica também revelou que as sequências Sq1 - Sq2 são caracterizadas por clinoformas progradantes, preservadas apenas distalmente na plataforma, compatíveis com a interpretação de migração em direção ao mar de ambientes costeiros/marinhos rasos; estas feiçóes têm suas superfícies-topo truncadas por superfícies que se amalgamam à superfície $S 1$ para formarem superfícies diácronas de extensão plataformal, que testemunham a destruição parcial das sequências, e formam degraus erosivos progressivamente mais profundos em direção ao talude. No caso das sequências Sq3 - Sq4, as clinoformas distais encontram-se em continuidade lateral com unidades proximais que exibem fácies sísmicas do tipo hummocky, indicativas de ambientes fluvio-estuarinos parcialmente preservados na plataforma interna-média. Contudo, estas sequências são também dominadas por superfícies-topo erosivas formando uma sucessão de degraus que se aprofundam em direção à plataforma externa (Fig. 4). Estes conjuntos de elementos estratigráficos de Sq1 - Sq4 são indicativos de sequências deposicionais formadas sob condiçóes de regressão forçada (no sentido de Hunt \& Tucker 1992, Posamentier \& Morris 2000, Plint \& Nummedal 2000). Condiçôes de regressão forçada refletem o processo de diminuição contínua de nível de base (diminuição do espaço de acomodação) e de migração da linha de costa em direção ao oceano, como resposta direta à queda relativa de nível de mar, independentemente da taxa de aporte sedimentar. Neste contexto, cada sequência sísmica Sq1 - Sq4 foi interpretada como representando uma repetiçáo de ciclos deposicionais transgressivos-regressivos, caracterizados pela preservação de unidades regressivas mais espessas na parte distal do perfil deposicional e pela ausência, ou reduzida presença, de unidades transgressivas e de mar alto preservadas na parte proximal da margem. Assim, as superfícies S1 - S5 podem ser interpretadas como horizontes diácronos, originados em períodos de máxima regressão marinha e de extensa exposição subaérea da plataforma continental, subsequentemente retrabalhados durante períodos transgressivos (Cattaneo \& Steel 2003).

A análise sísmica também evidenciou que, apesar de representarem sequências individuais construídas em condiçóes de regressão forçada (sob condiçóes de diminuição do espaço de acomodação), as sequências deposicionais Sq1 - Sq4 se empilham numa sucessão estratigráfica fortemente agradacional, que atinge espessura de - 100 - $130 \mathrm{~m}$ na altura da plataforma externa (Figs. 4 e 5). Desta forma, o empilhamento do conjunto de sequências não promove significativa progradação da plataforma entre a deposição de Sq1 e Sq4, como normalmente ocorre durante condiçóes de regressão forçada. Este arranjo arquitetural evidencia que a preservação de empilhamento de sequências regressivas exigiria a ocorrência de subsidência regional, condição essencial para a criação de espaço de acomodação que permita o empilhamento e subsequente preservação de unidades agradacionais (Catuneanu 2006, Trincardi \& Correggiari 2000). As condiçóes de criação de espaço de acomodaçáo parecem ainda ter variado entre a deposiçáo de Sq1 para Sq4: enquanto o alcance interno das sequências Sq1 e Sq2 atinge somente a plataforma média, as sequências $\mathrm{Sq} 3$ Sq4 recobrem toda a plataforma em direção ao continente. A progressiva ampliação de deposição das sequências em direção ao continente, entre Sq1 e Sq4, aponta também claramente para a ocorrência de movimentos flexurais crescentes da plataforma continental (basculamento), entre a deposiçáo da Sq1 e da Sq4, induzidos possivelmente por sobrecarga sedimentar diferencial e/ou compactaçáo (Posamentier \& Morris 2000). Esta tendência agradacional do conjunto de sequências deposicionais é claramente observada pela trajetória ascendente da posição dos respectivos pontos de inflexão entre unidades de paleoplataforma e de paleotalude superior das sequências (a chamada trajetória dos offlap breaks nas Figs. 4 e 5). Além disso, a análise sísmica evidenciou maior preservação de espessura sedimentar na plataforma externa da porção norte $(\sim 130 \mathrm{~m})$, que na plataforma externa da porção sul $(\sim 110 \mathrm{~m})$. Esta diferença de espessura sedimentar preservada, aliada à geometria de suas clinoformas (com tendência sigmoidal), testemunham condiçôes suplementares de criação de espaço de acomodação na porção norte da plataforma, à frente do sistema deltaico emerso do Rio Paraíba do Sul (Fig. 5). Esta disponibilidade de maior espaço de acomodação relativa é ainda indicada pela morfologia depressionada da plataforma da porção norte da área, como ilustra o recuo da isóbata de 100 m logo a sul do Cabo de Sáo Tomé (Figs. 1 e 4).

No topo da sucessão estratigráfica analisada, a arquitetura sísmica da sequência Sq5 permite sua interpretação 
como unidades sedimentares depositadas em condições transgressivas e de mar alto. Esta sequência mais jovem recobre quase toda a plataforma continental sob forma de depósitos tabulares agradacionais distribuídos até a profundidade $(-75-100 \mathrm{~m}$, a partir de onde o fundo submarino é dominado pela sequência $\mathrm{Sq} 4$. As feições lineares presentes ao longo das isóbatas de $70-80 \mathrm{~m}$ são arquiteturalmente caracterizadas por feiçôes prismáticas acopladas a pináculos carbonáticos (Fig. 6A e B). Estas feições representam possivelmente paleolinhas de costa construídas durante a última transgressão marinha em contexto de grande aporte fluvial. Vale ressaltar que feiçóes prismáticas transgressivas são observadas principalmente na base das sequências Sq3 e Sq4 na porção sul da plataforma, indicando que esta porção esteve sob a influência direta do aporte sedimentar do Rio Paraíba do Sul durante a deposição deste intervalo estratigráfico, apontando para prováveis posiçóes de paleo desembocaduras do rio a sul do Cabo de São Tomé (Figs. 1, 4 e 5), como sugerem também as maiores espessuras relativas das sequências Sq3 e Sq4 na plataforma sul da Bacia de Campos.

\section{Cronoestratigrafia e ciclicidade deposicional}

A ausência de dados de testemunhagem na área impede uma datação absoluta ou bioestratigráfica das sequências Sq1 - Sq5. Os únicos dados disponíveis advêm de correlaçóes cronoestratigráficas fornecidas por um poço de sondagem exploratória da indústria de óleo (poço RJS-001-RJ), localizado a $49 \mathrm{~m}$ de profundidade de lâmina d'água na plataforma da área de estudo (Fig. 1). Este poço fornece excepcionalmente informações sobre a janela estratigráfica quaternária, normalmente descartada para datação e análises bioestratigráficas pela indústria. A correlação da base de dados do presente trabalho, com uma base de dados sísmicos calibrados estratigraficamente por Silva (1992) com os dados do poço RJS-001-RJ, oferece informaçôes bioestratigráficas que auxiliam na aproximação do intervalo temporal de deposição das sequências Sq1 - Sq5 (Figs. 1 e 3). O cruzamento das duas bases de dados permitiu a correlação da superfície $S 1$ com uma superfície erosiva regional, o chamado Marco P de Silva (1992), correlacionado pelo autor a uma superfície formada há 440 - 500 ka A.P. Mas na verdade, de acordo com Shimabukuro (1989 apud Silva 1992), sedimentos coletados a $150 \mathrm{~m}$ abaixo do fundo submarino, ao nível do horizonte $\mathrm{P}$, indicaram a presença de Pseudoemiliania lacunosa, correlacionada ao topo da biozona N710 (correspondente à biozona NN19 de Martini 1971), cuja ocorrência distribui-se ao longo de um grande intervalo entre 910 - 440 ka A.P. (Pleistoceno Inferior/Médio, usando definiçôes temporais de Gradstein, Ogg \& Schmitz 2012; Fig. 3). Argumenta-se aqui, que se tal intervalo corresponde de fato ao topo da biozona N710 (Fig. 3), a superfície S1 estaria de fato posicionada em torno de 440 - 500 ka A.P., como apontado por Silva (1992). Para tal, seria necessária a ocorrência de espécies mais jovens que $440 \mathrm{ka}$ diretamente acima do horizonte P, como por exemplo, Gephyrocapsa oceanica (Antunes 1994), que não são relatadas por Shimabukuro (1989 apud Silva 1992). Além disso, o horizonte erosivo P reflete provavelmente variaçóes substanciais de idades, relacionadas a distintos graus de erosão entre porçóes proximais e distais da margem, assim como lateralmente ao longo da plataforma. Apesar disto, estes dados permitem estimar uma idade quaternária para a superfície de exposição regional S1 entre 910 - 440 ka A.P.

Por outro lado, a análise sísmica efetuada neste estudo mostra que acima da superfície S1 encontramse empilhadas cinco sequências deposicionais (Sq1 Sq5; Figs. 4 e 5). Além disso, desde os últimos $-500 \mathrm{ka}$ (Imbrie et al. 1984, Medina-Elizalde \& Lea 2005, Clark et al. 2006), há uma persistência global de ciclos deposicionais de $4^{\mathrm{a}}$ ordem, de cerca de $100-120$ ka de duração e \pm 100 - 145 m de amplitude de oscilação do sinal eustático, como evidenciados pela compilação de curvas globais de variaçôes eustáticas, baseadas nas razóes isotópicas de $\delta^{18} \mathrm{O}$ correlacionadas a estágios isotópicos marinhos, compiladas por Rabineau et al. (2006) (Fig. 7). Este conjunto de correlaçôes aponta assim, para um intervalo de deposição das sequências Sq1 - Sq5 nos últimos - $440-500$ ka. Neste contexto, as sequências Sq1 - Sq4 englobariam temporalmente a sucessão de estágios isotópicos marinhos 12 a 2 (Fig. 7B), ou seja a sequência Sq1 teria se depositado entre os estágios isotópicos 12 e 10 (entre - 430 - 450 e 330 - 350 ka A.P.); a sequência Sq2 entre os estágios 10 e 8 (entre - 330 - 350 e 230 - 250 ka A.P.); a sequência Sq3 entre os estágios 8 e 6 (entre - $230-250$ e 130 - 140 ka A.P.); a sequência Sq4 entre os estágios 6 a 2 (entre - 130 - 140 e $30-20$ ka A.P.). A sequência Sq5 teria se desenvolvido a partir do estágio isotópico 2 (último máximo glacial), representando a deposição marinha que acompanha a última deglaciação, iniciada globalmente entre $-18-20 \mathrm{ka}$ (Pleistoceno Tardio-Holoceno), sendo representada por unidades transgressivas (fácies plano-paralelas e hummocky; Figs. 4 e 5) e de mar alto (prismas proximais progradantes na Fig. 5). As construçôes carbonáticas da plataforma externa, assentadas sobre as unidades siliciclásticas, são 


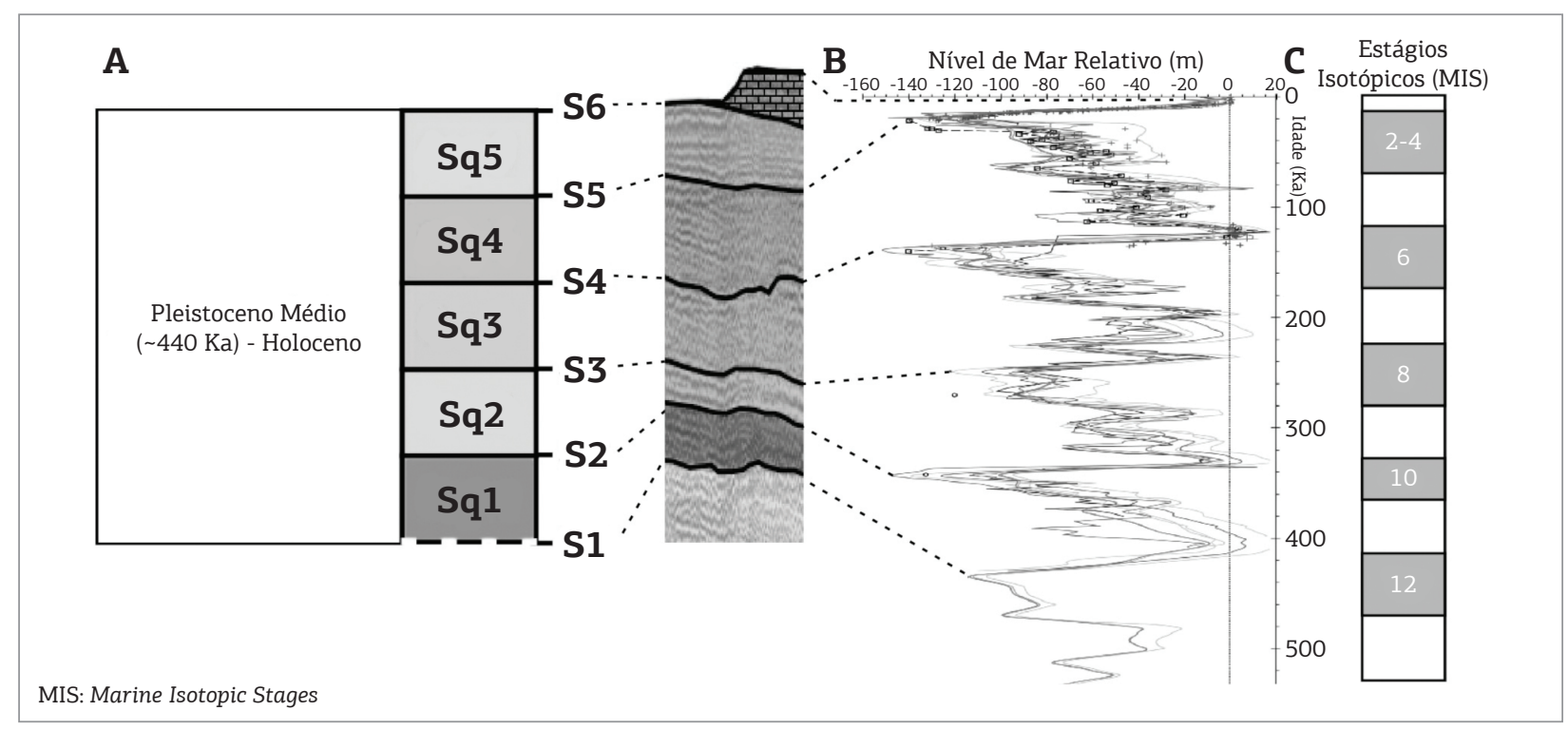

Figura 7. (A) Coluna estratigráfica proposta para a seção rasa da plataforma continental sul da Bacia de Campos, calibrada com auxílio de dados de poço (Fig. 3). (B) Coluna vertical das seções sísmicas da área de estudo, correlacionada estratigraficamente com $(C)$ curvas globais de variação isotópica de $\delta^{18} O$ relacionadas a estágios isotópicos marinhos (Marine Isotopic Stages), compiladas por Rabineau et al. (2006), calibradas pela datação de feições morfológicas, diagenéticas e orgânicas em plataformas continentais.

interpretadas como parte do trato transgressivo. A sequência Sq5 representa deste modo um meio-ciclo deposicional (uma sequência ainda em formação).

Esta proposição de ciclicidade deposicional de quarta ordem é ainda consistente com as evidências encontradas em outras margens quaternárias ao redor do mundo, onde ciclos eustáticos de alta amplitude $( \pm 100-145 \mathrm{~m})$ representam o principal controle nos ciclos deposicionais e padróes de acamamento interno de plataformas continentais estáveis (exemplo, Trincardi \& Correggiari 2000, Ridente \& Trincardi 2002, Rabineau et al. 2005, Tripsanas \& Piper 2008).

\section{CONCLUSÃO}

A análise de cerca de $3.000 \mathrm{~km}$ de linhas sísmicas monocanal (sparker $500-1.000 \mathrm{~J}$ ) permitiu a investigação e proposição de um primeiro arcabouço estratigráfico e de arquitetura estratal para as sequências sísmicas que compóem o registro sedimentar raso $(-250 \mathrm{~m})$ da plataforma continental da porção sul da Bacia de Campos.

Cinco sequências sísmicas principais foram reconhecidas e mapeadas (Sq1 - Sq5), formando uma sucessão de sequências dominantemente regressivas que se espessa em direção ao mar, desenvolvidas essencialmente em condiçóes de regressão forçada. Estas sequências são limitadas por discordâncias erosivas amplamente distribuídas (horizontes S1 - S5), esculpidas durante longos períodos de total exposiçáo subaérea da plataforma, indicando condiçôes de diminuição de nível de base e destruição parcial de espaço de acomodação sedimentar. Apenas a sequência superficial Sq5, restrita à plataforma continental, é constituída por elementos estratigráficos indicativos de sequência eminentemente transgressiva.

A correlação entre a interpretação dos dados sísmicos, dados cronoestratigráficos de poço exploratório e curvas de variaçóes eustáticas globais baseadas nas razôes isotópicas de $\delta^{18} \mathrm{O}$ (estágios isotópicos marinhos), apoia a hipótese de que as sequências sísmicas Sq1 - Sq4 sejam sequências deposicionais que registram ciclos glacio-eustáticos de cerca de 100 - 120 ka de duração, desenvolvidas entre os estágios isotópicos marinhos 12 e 2 (Pleistoceno Médio-Superior). A Sq5 é interpretada como uma sequência ainda em desenvolvimento, caracterizada por depósitos do Pleistoceno Tardio-Holoceno, depositada desde a última transgressão marinha.

No entanto, embora a deposição das sequências Sq1 - Sq4 em condiçóes de regressão forçada indique a destruiçãao de espaço de acomodação durante cada ciclo glacio-eustático de $-100-120$ ka de duração, o empilhamento destas sequências não implicou em progradação significativa da plataforma continental. O caráter agradacional da sucessão estratigráfica Sq1 - Sq4 
indica que a deposição do conjunto de sequências foi promovida por uma combinaçấo de ciclos de regressão forçada, acompanhados de contínua criação de espaço de acomodação na plataforma durante os últimos - 500 ka, capaz de preservar uma sucessáo vertical de - 25 - $30 \mathrm{~m}$ de paleoambientes fluvio-estuarinos na plataforma interna-média e de $-100-130 \mathrm{~m}$ espessura de ambientes costeiros/marinhos rasos na altura da plataforma externa. Além disso, a ampliação do alcance interno das sequências preservadas entre Sq1 até $\mathrm{Sq} 5$ indica um mecanismo de progressivo basculamento da plataforma externa durante o período. A criaçấo de pelo menos $100 \mathrm{~m}$ de espaço de acomodação sedimentar no intervalo de $-500 \mathrm{ka}$ aponta para a existência de um regime persistente de subsidência flexural da margem, talvez explicado por sobrecarga diferencial das sequências depositadas sob forte influência deltaica e de aporte fluvial do Rio Paraíba do Sul desde o final do Terciário Inferior, com contribuição subsidiária de criaçáo de espaço de acomodação por compactaçáo sedimentar. Além disso, a preservação de maiores espessuras sedimentares durante a deposiçáo das sequências $\mathrm{Sq} 4$ - Sq5 na porção sul da plataforma, aliada à presença de grande número de feiçôes típicas de plataforma sob influência de regime deltaico (prismas transgressivos na base das sequências) atesta a influência do aporte do Rio Paraíba do Sul direcionado para a regiáo a sul do Cabo de São Tomé nos últimos 130 ka.

\section{AGRADECIMENTOS}

Os autores agradecem à Coordenação de Aperfeiçoamento de Pessoal de Nível Superior (CAPES), Edital Ciências do Mar, Processo no 23038.051609/200961, à Fundação de Amparo à Pesquisa do Estado do Rio de Janeiro (FAPERJ) Processos no E-26/110.812/2008 e E-26/102.254/2009) e ao Conselho Nacional de Desenvolvimento Científico e Tecnológico (CNPq) Edital Universal, Processo no 476183/2010-3) pelo apoio financeiro concedido para a realização deste trabalho. Ao Instituto de Estudos do Mar Almirante Paulo Moreira (IEAPM), parceiro no projeto CAPES-Ciências do Mar, que possibilitou a aquisição dos dados da Operação Rio Costa II a bordo do navio AvPq Aspirante Moura, cedido em substituição ao Navio Cruzeiro do Sul, originalmente previsto em função de projeto agraciado em edital financiado pelo Ministério da Ciência, Tecnologia e Inovação (MCTI) e a Marinha do Brasil para disponibilização de tempo de navio para pesquisas oceanográficas a bordo do Navio Cruzeiro do Sul. À CAPES pela bolsa de mestrado concedida ao primeiro autor, assim como ao CNPq pela concessão de bolsas de pesquisa ao segundo e terceiro autores. Finalmente, agradecemos a colaboraçấo de revisores anônimos, cujos comentários contribuíram para a melhoria geral do manuscrito. Esta é uma contribuição do Grupo de Pesquisa Geologia e Oceanografia de Margens Continentais Passivas - http:// www.geomargem.org.

\section{REFERÊNCIAS}

Alves E.C., Gorini M.A., Rodrigues P.C.H., Silva, C.G. 1980. Estudo da sedimentação Quaternária na região entre Rio Doce e Cabo Frio. In: CBG, XXXI Cong. Bras. Geologia, p. 515-529.

Antunes V.S. 1994. Bioestratigrafia dos nanofósseis quaternários da bacia de Campos. Boletim de Geociências da Petrobras, 8(2/4):295-313.

Bard E., Hamelin B., Fairbanks R.G. 1990. U-Th ages obtained by mass spectrometry in corals from Barbados: sea level during the past 130,000 years. Nature, 346:456-458.

Bassinot F., Labeyrie L., Vincent E., Quidelleur X., Lancelot N.J., Lancelot Y. 1994. The astronomical theory of climate and the age of the Brunhes-Matuyama magnetic reversal. Earth Planetary Science Letters, 126:91-108

Bernardo G.A. 2012. Estratigrafia sísmica dos sistemas de plataforma rasa entre Macaé e cabo de São Tomé-RJ. Dissertação de Mestrado. Programa de Pós-graduação em Geologia e Geofísica Marinha, Universidade Federal Fluminense, Niterói, $125 \mathrm{p}$.

Berné S., Rabineau M., Flores J.A., Sierro F.J. 2004. The impact of quaternary global changes on strata formation - Exploration of the shelf edge in the northwest Mediterranean sea. Oceanography, 17(4):92-103.

Cainelli C. \& Mohriak W.U. 1999. Some remarks on the evolution of sedimentary basins along the Eastern Brazilian continental margin. Episodes, 22(3):206-216.

Cattaneo A. \& Steel R.J.T. 2003. Transgressive deposits: a review of their variability. Earth Science Reviews, 62:187-228.

Catuneanu O. 2006. Principles of sequence stratigraphy. Oxford, Elsevier, $375 \mathrm{p}$.

Chang H.K., Kowsmann R.O., Figueiredo A.M.F., Bender A. 1992. Tectonics and Stratigraphy of the East Brazil Rift System: an Overview. Tectonophysics, 213:97-138.

Clark P.U., Archer D., Pollard D., Blum J.D., Jose A.R., Brovkin V., et al. 2006. The middle Pleistocene transition: characteristics, mechanisms, and implications for long-term changes in atmospheric pCO2. Quaternary Science Reviews, 25:3150-3184.

Fairbanks R.G. 1989. A 17,000-year glacio-eustatic sea level record: influence of glacial melting rates on the Younger Dryas event and deep-ocean circulation. Nature, 342:637-642. 
Figueiredo A.G. Jr, Tessler M.G. 2004. Topografia e composição do substrato marinho da Região Sudeste-Sul do Brasil. Technical Report, Série Documentos Revizee - Score Sul, Instituto Oceanográfico, Universidade de São Paulo, 64 p.

Gradstein F.M., Ogg J.G., Schmitz M. 2012. The Geologic Time Scale. London, Elsevier, 1176 p

Grossman E.E., Eittreim S.L., Field M.E., Wong F.L. 2006. Shallow stratigraphy and sedimentation history during high-frequency sea-level changes on the central California shelf. Continental Shelf Research, 26:1217-1239.

Henriksen S., Helland-Hansen W., Bullimore S. 2011. Relationships between shelf-edge trajectories and sediment dispersal along depositional dip and strike: a different approach to sequence stratigraphy. Basin Research, 23:3-21.

Hernandez-Molina F.J., Somoza L., Lobo F. 2000. Seismic stratigraphy of the Gulf of Cadiz continental shelf: a model for late Quaternary high resolution Seismic Stratigraphy. In: Hunt, D. e Gaythorpe, R. (Eds.). Seismic response to forced regression. Geological Society Special Publication, 172:329-362.

Hunt D. \& Tucker M.E. 1992. Stranded parasequences and the forced regressive wedge systems tract: deposition during base-level fall. Sedimentary Geology, 81:1-9.

Imbrie J., Hays J.D., Martinson D.G., Mcintyre A., Mix A.C., Morley J.J., et al. 1984. The orbital theory of Pleistocene climate: support from a revised chronology of the marine $\delta 018$ record. In: A. Berger, J. Imbrie, J. Hays, G. Kukla, B. Saltzman (eds.). Milankovitch and climate. Series C: Mathematical and Physical Sciences, 126, Kluwer Academic Publishers, Hingham, Mass., p. 269-305.

Jin J.H., Chough S.K., Ryang W.H. 2002. Sequence aggradation and systems tracts partitioning in the mid-eastern Yellow Sea: roles of glacio-eustasy, subsidence and tidal dynamics. Marine Geology, 184:249-271.

Kowsmann R., Vicalvi M., Costa M. 1979. Considerações sobre a sedimentação quaternária na plataforma continental entre Cabo Frio e o rio Itabapoana. Notícia Geomorfológica, 19(37-38):41-58

Labeyrie L.D., Duplessy J.C., Blanc P.L. 1987. Variations in mode of formation and temperature of oceanic deep waters over the past 125,000 years. Nature, 327(6122):477-482.

Lambeck K., Chappell J. 2001. Sea level change through the Last Glacial Cycle. Science, 292:679-686.

Liquete C., Canals M., De Mol B., De Batist M., Trincardi F. 2008. Quaternary stratal architecture of the Barcelona prodeltaic continental shelf (NW Mediterranean). Marine Geology. 250(3-4/1):234-250

Lofi J., Rabineau M., Gorini C., Berné S., Clauson G., Clarens P., et al. 2003. Plioquaternary prograding clinoform wedges of the western gulf of lions continental margin (NW Mediterranean) after the messinian salinity crisis. Marine Geology, 198(3-4):289-317.

Lopes A.L. M. 2004. Análise da evolução sedimentar quaternária da plataforma continental sul da bacia de Campos com base em estratigrafia sísmica e sonografia. Dissertação de Mestrado, Programa de Pós-graduação em Geologia e Geofísica Marinha, Universidade Federal Fluminense, Niterói, 66 p.

Maia R.M.C., Reis A.T., Alves E.C., Silva C.G., Gorini C., Silva A., et al. 2010. Architecture and depositional cyclicity of Quaternary continental shelf systems, Santos and Campos Basins - Brazil. Brazilian Journal of Oceanography, 58 (spe 1):15-29.

Marangoni, M.B. 2012. Arcabouço estratigráfico e ciclicidade deposicional dos sistemas sedimentares quaternários da plataforma sul da Bacia de Campos (RJ). Dissertação de Mestrado, Programa de
Pós-graduação em Oceanografia, Universidade do Estado do Rio de Janeiro, Rio de Janeiro, 141 p.

Martini E. 1971. Standard Tertiary and Quaternary calcareous nanoplankton zonation. In: Farinaci, A. (ed). Conference of planktonic microfossils. Roma, Proceedings.... Edizioni Tecnoscienza, 2:739-785.

Medina-Elizalde M. \& Lea, D.W. 2005. The Mid-Pleistocene Transition in the Tropical Pacific. Science, 310:1009-1012.

Mitchum R.M. Jr., Vail P.R., Sangree, J.B. 1977a. Seismic stratigraphy and global changes of sea level; Part 6, Stratigraphic interpretation of seismic reflection patterns in depositional sequences. In: Payton C.E. (ed). Seismic Stratigraphy: Application to Hydrocarbon Exploration. American Association of Petroleum Geologists Memoir, 26:117-133.

Mitchum R.M. Jr., Vail P.R., Sangree, J.B. 1977b. Seismic stratigraphy and global changes of sea level, part 7: Seismic stratigraphy interpretation procedures. In: Payton C.E. (ed). Seismic Stratigraphy: Application to Hydrocarbon Exploration. American Association of Petroleum Geologists Memoir, 26:135-143.

Modica C.J. \& Brush E.R. 2004. Postrift sequence stratigraphy, paleogeography, and fill history of the deep-water Santos Basin offshore southeast Brazil. AAPG Bulletin, 88(7):923-945.

Passos M.M. 2012. Estratigrafia sísmicas dos sistemas costeiros e plataformais rasos entre São Tomé e Itabapoana-RJ. Dissertação de Mestrado; Programa de Pós-graduação em Geologia e Geofísica Marinha, Universidade Federal Fluminense, Niterói, 95p.

Plint A.G. \& Nummedal D. 2000. The falling stage systems tract: recognition and importance in sequence stratigraphy. In: Hunt D. \& Gawthorpe R.L. (ed). Sedimentary responses to forced regressions. Geological Society, Special Publications, 172:1-17.

Posamentier H.W. \& Morris W.R. 2000. Aspects of the stratal architecture of forced regressive deposits. In: Hunt D \& Gawthorpe R.L. (ed). Sedimentary responses to forced regressions. Geological Society, Special Publications, 172:19-46

Rabineau M., Berné S., Aslanian D. Olivet J-L, Joseph P. Guillocheau F., et al. 2006. Paleo sea levels reconsidered from direct observation of paleoshoreline position during Glacial Maxima (for the last 500,000 yr). Earth and Planetary Science Letters, 252:119-137.

Rabineau M., Berné S., Aslanian D., Olivet J-L., Joseph P., Guillocheau F., et al. 2005. Sedimentary sequences in the Gulf of Lions: a record of 100,000 years climatic change. Marine and Petroleum Geology, 22(6-7):775-804

Ridente D. \& Trincardi F. 2002. Eustatic and tectonic control on deposition and lateral variability on Quaternary regressive sequences in the Adriatic basin (Italy). Marine Geology, 184:273-293.

Shackleton N.J. 2000. The 100,000-year Ice-Age cycle identified and found to lag temperature, carbon dioxide, and orbital eccentricity. Science, 289:1897-1902.

Silva A. 1992. Evolução sedimentar pós-miocênica na área nordeste da Bacia de Campos, Rio de Janeiro. Dissertação de Mestrado, Universidade Federal do Rio de Janeiro, Rio de Janeiro, 57 p.

Tesson M., Posamentier H.W., Gensous B. 1993. Late Pleistocene shelf-perched lowstand wedges on the Rhône continental shelf. In: H. W. Posamentier, C.P. Summerhayes, B.A. Hacq, G.P. Allen (eds.). Sequence stratigraphy and facies association. IAS Special Publication 18, Blackwell Science, Oxford, p. 183-196.

Tesson M., Posamentier H.W., Gensous B. 2000. Stratigraphic organization of late Pleistocene deposits of the Western part of the Golfe du Lion shelf (Languedoc shelf) Western Mediterranea Sea, using high-resolution seismic and core data. AAPG Bulletin, 84:119-150 
Tezcan D., Okyar M. 2006. Seismic stratigraphy of Late Quaternary deposits on the continental shelf of Antalya Bay, Northeastern Mediterranean. Continental Shelf Research, 26(14):1595-1616.

Trincardi F. \& Corregiari A. 2000. Quaternary forced-regression deposits in the Adriatic basin and the record of composite sealevel cycles. In: Hunt D., Gawthorpe R.L. (ed). Sedimentary responses to forced regressions. Geological Society, Special Publications, 172:245-269.

Tripsanas E.K. \& Piper D.J.W. 2008. Late Quaternary stratigraphy and sedimentology of Orphan Basin: Implications for meltwater dispersal in the southern Labrador Sea. Palaeogeography, Palaeoclimatology, Palaeoecology, 260(3-4):521-539.

Waelbroeck C., Labeyrie L.D., Michel E., Duplessy J-C., McManus J., Lambeck K., et al. 2002. Sea level and deep water changes derived from benthic Foraminifera isotopic record. Quaternary Science Reviews, 21(1-3):295-305.

$\overline{\text { Arquivo digital disponível on-line no site www.sbgeo.org.br }}$ 